H. Ishida, R. Tuttle, M. Pickford, N. Ogihara, M. Nakatsukasa (eds.)

\title{
Human Origins and Environmental Backgrounds
}

Series: Developments in Primatology: Progress and Prospects

Springer, New York 2006

IX + 281 pp., 83 fig., hardcover; GBP 92.50

ISBN 978-0-387-29638-8

This book is dedicated to Hidema Ishida whose studies of primate locomotion and paleoanthropology spanned some 40 years prior to his retirement in 2003, the occasion of which was marked by a symposium that forms the basis of the current volume of papers. The book has 3 broad themes: fossil hominoids and paleoenvironments; functional morphology, and theoretical approaches, and while the quality and originality of the contributions is considerably mixed, the volume offers a broad synthesis of the research of a multidisciplinary, multinational team of researchers who have collaborated on a range of topics of interest to a wide spectrum of researchers of primate evolution.

Central to many of the papers are aspects surrounding the evolution of human bipedalism. These contributions range from a biomechanical comparison of the femora of rats subjected to quadrupedal and bipedal training, to computer simulations, to habitat reconstruction and environmental pressures. Those that explore potential selective pressures for the evolution of bipedalism in forest habitats are particularly interesting and Pickford's appraisal of the paleoenvironment in which bipedalism probably evolved and paleoecological factors relevant to its evolution is a particular highlight.

The greatest strength of this volume is that it combines reviews of past developments (e.g. Tuttle's overview of seven decades of the machinations of discovering, interpreting and reinterpreting East African Miocene fossil anthropoids), with a discussion of current topical issues (such as recent hypotheses that bipedalism evolved in an arboreal habitat), while further outlining gaps in our knowledge and directions for future research. As such, it is an excellent allround book for researchers and graduate students that clearly identifies the future challenges in our understanding of human evolution.

The production of the volume is, however, less impressive. The hardback issue costs nearly GBP 100, but consists of small text on thin paper with often poorly reproduced illustrations. In this respect, it is grossly overpriced. On the other hand, key papers in the volume make a considerable contribution towards a better understanding of the relationship among environmental changes, adaptive mechanisms and human origins, and for this reason readers interested in the topic will find new perspectives and new directions in its pages.

\begin{tabular}{ll}
\hline KARGER & ( ) 2007 S. Karger AG, Basel \\
Fax +4161506 12 34 & \\
$\begin{array}{l}\text { E-Mail karger@karger.ch } \\
\text { www.karger.com }\end{array}$ & $\begin{array}{l}\text { Accessible online at: } \\
\text { www.karger.com/fpr }\end{array}$
\end{tabular}

